\title{
Vorwort zur 10. Auflage
}

Als vor nunmehr 44 Jahren die "Sprachdummheiten von Gustav Wustmann herauskamen, erwies sich diese „Kleine deutsche Grammatik des Zweifelhaften, des Falschen und des Häßlichen " - so erläuterte das Titelblatt bald als starkes Boilwerk der Sprachfreunde in dem damals mit frischen Waffen geführten Kampf um eine Besserung der Muttersprache, und der Name Wustmann wurde sinnbildlich für das Gebaren schneidigen Angriffs auf diesem Gebiet. Es war ein selbstverständlicher Vorgang, daß mit der Zeit der alte Ruhm des Buches matter wurde, da neue Männer auf dem Plan erschienen und die einst gerügten Falschheiten und Häßlichkeiten der Sprache sich wenigstens zu einem Teil besserten oder - anderen Platz machiten. Zudem war die polternde Urwüchsigkeit des „Wustmann“, die ihm sein Gepräge und seinen Erfolg gegeben hatte, durch die mannigfachen Umarbeitungen von neun Auflagen abgeschwächt oder wohl ganz verloren gegangen.

Wenn der Verlag sich daraufhin zu einer vollständigen Erneuerung des Buches entschloß, so erwuchsen dem Bearbeiter viele Aufgaben. Es galt, die ursprünglichen frischen Farben wieder zum Vorschein zu bringen : tatsächlich greift die vorliegende Ausgabe nicht selten auf die erste zurück; es galt vor allem, die neuen und neuesten sprachlichen Erkenntnisse fruchtbar $\mathfrak{z u}$ machen. Es durfte nicht unberücksichtigt bleiben, was der Kreis der im Sprachverein wirkenden Männer erreicht hatte, was die Schriften der Matthias, Engel, Eitzen oder zuletzt der Schmidt-Rohr, Schneider, Stęche, Weisgerber, Stoltenberg für Anregungen brachten. Es ging nicht mehr an, an der Enge der Forderungen fest- 
zuhalten, mit denen Wustmann, im Geiste der damaligen Wissenschaft, an die Spracherscheinungen herangetreten war, und die lebendige Sprache in dem Schnürleib zu halten, den die Mode längst abgeworfen hat. Ihre Eigengesetzlichkeit mußte voll anerkannt, in ihr natürliches Wachstum durfte nur da regelnd eingegriffen werden, wo Lässigkeit oder Ubbermut drohten, wertvollen alten Bestand zu gefährden. Gegen die wirklichen Sprachdummheiten unserer Zeit aber führt auch der neue Wustmann einen rücksichtslosen Kampf. Der Inhalt und Umfang des Buches mag zeigen, wieviel Unkraut noch immer auf dem deutschen Sprachboden wuchert. Gerade hier kann zimperliches Zugreifen nicht weiter führen; sollte sich jemand dabei getroffen fühlen, dann erinnern wir ihn an das Wort des alten Lichtenberg: Es ist unmöglich, die Fackel der Wahrheit durch ein Gedränge zu, tragen, ohne hier einen Bart und dort ein Kopfzeug zu versengen.

Der Wunsch, den alten zu einem wirklich „Neuen Wustmann ${ }^{4} z u$ verjüngen, hat denn auch zu einer starken Umänderung des Früheren geführt. Was nicht mehr galt, mußte fallen; 18 Abschnitte wurden eingefügt, viele andere, wie die "Modewörter" oder "Fremdwörter", gänzlich umgearbeitet, im ganzen über die Hälfte neu geschrieben.

Immer vernehmlicher klingt seit der Aufrichtung des dritten Reiches der Ruf durch Deutschland, auch auf dem Gebiet der Muttersprache den Kampf um das Bodenständige und echt Deutsche entschieden aufzunehmen. Verschweigen wir uns nicht, daß hier noch viel im argen liegt. Der Kampf um ein artgemäß schlichtes, klares und reines Deutsch darf nicht nur hier und da, er muß überall und jederzeit und von jedem Deutschen geführt werden. Der neue Wustmann will ein Helfer in diesem Kampfe sein.

Dr. Werner Schulze 